\section{Concentration of dilute haemoglobin solutions with Sephadex ${ }^{1}$}

B. DEUTSCH, R. D. LEVERE, and J. LEVINE From the Department of Medicine, State University of New York, Downstate Medical Center, New York

Sephadex provides a rapid and efficient means of concentrating haemoglobin solutions without significantly altering the original $p \mathrm{H}$ or causing denaturation of the protein. Sephadex consists of small grains of a crosslinked polysaccharide (dextran) which is hydrophilic and has polar properties due to a high content of hydroxyl groups. The degree of cross-linkage determines the porosity, with these properties bearing an inverse relationship. As a result of its hydrophilic character, Sephadex has a great affinity for water and swells when placed in aqueous solutions. The amount of water held is related to the cross-linkage. The quantity of captured water is expressed as water regain and recorded as grams of water per gram of dry gel. The solute of salt solutions can diffuse relatively freely through the gel grains, while large molecules, e.g., haemoglobin, are completely excluded. These properties of Sephadex have been most extensively utilized for gel filtration and chromatography although they lend themselves well to the concentration of solutions. Flodin, Gelotte, and Porath (1960) have described the use of Sephadex in concentrating the high molecular weight solute, cellulose.

\section{TECHNICAL}

To concentrate haemoglobin solutions of an initial volume greater than $10 \mathrm{ml}$., $1 \mathrm{~g}$. of Sephadex G-25 (water regain $2 \cdot 5 \mathrm{~g} \cdot \mathrm{H}_{2} \mathrm{O} / \mathrm{g}$. dry gel) is used for each $5 \mathrm{ml}$. of solution. With volumes smaller than $10 \mathrm{ml} .1 \mathrm{~g}$. of Sephadex is used for each $6 \mathrm{ml}$. of solution. The Sephadex is added to the haemoglobin solution and the mixture stirred for $\mathbf{1 0}$ minutes. Following this the slurry is poured into a scintered glass funnel and collected under vacuum. Some of the water and salts are now 'bound' by the Sephadex whereas haemoglobin is not and passes into the collecting flask. The collecting vessel is then changed and, if a red colour persists in the gel, an additional 1 to $2 \mathrm{ml}$. of the original haemoglobin solvent is added to the funnel to clear the slurry of any remaining haemoglobin.

This technique will increase the concentration of the original solution approximately three-fold and can be repeated as many times as desired to obtain the required concentration. With each concentration new gel grains should be used. The grains can be regenerated after use by washing with acetone and then allowing them to dry. With haemoglobin solutions of $120 \mathrm{mg}$. \%, obtained after elution from a starch block, a concentration to $1 \cdot 8 \mathrm{~g} . \%$ has been accomplished after three passages through

Received for publication October 161962

'Supported by U.S.P.H.S. grant no. HE-07346-01

9*

\section{Book reviews}

FLUORESCENT PROTEIN TRACING Edited by R. C. Nairn. (Pp. Xv + 279; illustrated. 42s.) Edinburgh and

London: E. \& S. Livingstone Ltd. 1962.

The idea of using the specificity of antibodies for identifying antigens at the cellular level goes back at least to 1934, when J. R. Marrack showed that anti-typhoid antibody conjugated with an azo-dye would specifically bind to and stain the bacilli. The intensity of the staining, however, was insufficient to be of practical use.

In $1942 \mathrm{~A}$. H. Coons, with the help of the experience of Creech in conjugating serum proteins with fluorescent carcinogenic hydrocarbons, succeeded in conjugating antibody with fluorescein and demonstrating that by means of it pneumococci could be specifically and beautifully identified in fixed tissue sections. The significance of this work must have been obvious, but the technique at the time appeared to be limited to demonstrating antigens which would withstand conventional fixation and embedding procedures; adequate fluorescence microscopes were uncommon in biological laboratories; fluorescein isocyanate for conjugation was not easy to prepare; and the idea that antibodies could be chemically manipulated with comparative ease and without loss of their specificity was unfamiliar to those most likely to benefit from their use. Ten years later Coons and his colleagues showed that fluorescent antibody methods could be applied to cryostat sections of frozen tissue, fixed sufficiently gently to retain the antigenic properties even of proteins; they had overcome many of the difficulties due to non-specific staining; and, most exciting of all, by means of the now familiar 'sandwich' technique they could even identify specific antibodies within individual cells. From this time onwards doubts and inhibitions on the part of others were thrown overboard, cryostat microtomes and suitable optical equipment began to appear in research, and even in routine laboratories, fluorochromes became available which were simpler to use, and a great harvest of theoretically and practically important information began to be reaped in many fields. The bibliography of 'Fluroescent Protein Tracing' con-

Concentration of dilute haemoglobin solutions with Sephadex-concluded

Sephadex. Recovery of haemoglobin, based on the original weight, has ranged between 85 and $90 \%$ with this method. Little to no change (0 to 0.05$)$ in the $p \mathrm{H}$ has been noted and haemoglobin denaturation, as evidenced by electrophoretic mobility, has not been apparent.

\section{REFERENCE}

Flodin, P., Gelotte, B., and Porath, J. (1960). Nature (Lond.), 188, 493 
tains some 680 references to papers on this subject, most of which have appeared during the past five years. Thus the fluorescent antibody technique has become the method of choice for the cytological localization and identification of viruses and bacteria in infected cells, and for recognizing structural and secretable macromolecular materials, e.g., hormones or tissue-specific antigens, in cells. It is also by far the easiest sensitive method for recognizing and tracing the detailed fate of foreign antigenic materials, unless these themselves are already labelled by means of fluorochromes or radio-active tracers. In clinical medicine and pathology, however, the most important use of fluorescent protein tracers has probably become not the purpose for which such tracers were originally introduced, namely to trace antigens, but to discover antibodies. By means of the fluorescent antiglobulin reagents it is a relatively simple matter to detect antibodies attached to elements in a tissue section or in a smear, and thus it has been possible to identify several anti-nuclear factors in sera of patients with systemic lupus erythematosus, several anti-thyroid antibodies in cases of lymphadenoid goitre, antibodies against parietal cells in pernicious anaemia, etc. Apart from the detection of auto-antibodies, the application of a similar technique to smears of Treponema pallidum treated with suspected syphilitic serum appears to provide a sensitive and specific test for antibodies against this microbe. The list of useful applications could be continued at great length.

The time was obviously ripe for the appearance of a book in which the practical details of the use of fluorescent protein tracers and their applications in practice would be drawn together, and this is what 'Fluorescent Protein Tracing' does. The Editor, R. C. Nairn, and his colleagues, C. S. Chadwick, J. E. Fothergill, K. B. Fraser, and M. G. McEntegart, have themselves been involved in numerous original developments in this field, and their book is obviously written by persons who have intimate practical experience of the problems involved. They include an amount of practical detail which will make the volume very useful to those who want to use the techniques themselves as well as to know about the results of other workers. The coverage of published work is good and well up to date and the aspects discussed include the chemical and optical properties of fluorochromes and their protein conjugates; fluorescence microscopy and photomicrography; the direct use of conjugated protein tracers; and various immunological applications to bacteria, protozoa, etc., to viruses and rickettsiae, and to tissue antigens and antibodies. Cytological and histological problems, on which the success of the method may stand or fall are gone into fully, on the basis of the author's own experience or reports from the literature. There are numerous illustrations, including some handsome colour reproductions, and the index is quite adequate. Although the authors write with understandable enthusiasm they temper this with caution where necessary, as is shown by the following passage (p. 159) dealing with applications of the technique for diagnostic bacteriology:- Many of the opinions expressed about the part immunofluorescence can play in diagnostic bacteriology seem over optimistic. No one will dispute the value of the method for the rapid recogni- tion of certain bacteria, but the use of fluorescent anti- $\stackrel{D^{\prime}}{=}$ body requires no less skill, experience and judgment than 은 any other bacteriological procedure, and any impression $\vec{\Rightarrow}$ that it will lead to a "push button" diagnostic service in $\stackrel{\text { }}{+}$ bacteriology is certainly misleading. The fluorescent $\bar{C}$ method, which has certain special advantages over므 traditional bacteriological procedures, for example, in $\overline{\bar{\sigma}}$ the recognition of non-viable organisms and in the simple $\overparen{\Phi}$ detection of non-precipitating antibody, now seems likely to become a useful technique available in all well- $\infty$ equipped centres, though more experience is required $\vec{\circ}$ before its place in diagnostic bacteriology can be defined.'

At a price of $42 s$. this book is good value, and is $\vec{\omega}$ thoroughly recommended.

J. H. HUMPHREY

THE ANATOMY OF THE CEREBROSPINAL FLUID. By J. W. ì Millen and D. H. M. Woollam. (Pp. viii $+151 ; 92 \underset{\omega}{\infty}$ figures. 50s.) London: Oxford University Press. 1962. $\frac{1}{\sigma}$ Cerebrospinal fluid has been made use of in the diagnosis 0 of disease since the beginning of the century and its potentiality in this direction is far from being exhausted. The pathologist in attempting to assess the significance of his findings, be they the result of examining this fluid $\widehat{\widehat{S}}$ or of studying histological preparations, comes up repeatedly against our present-day lack of knowledge concerning the physiology of the fluid. What part is $\omega$ played by the ependymal cells and what is the explanation $\square$ of the seemingly decreasing importance of their cilia as life advances? What is the source of the tau fraction? What is the precise nature of the reabsorption mechanism in the arachnoidal villi and what is the fate of the phago- $\frac{0}{D}$ cytic cells?

This monograph does not answer these questions, nor $\overrightarrow{\vec{B}}$ does it pose the many other problems that remain un- 3 solved: in fact little attention is paid to physiology. But it sets out simply yet exhaustively the anatomical facts and doubts concerning the structures comprising the ventricular system. (The title, although understand-? able and convenient, is strictly a misnomer.) The reader 0 will learn with interest for how long there was uncer- 3 . tainty about the precise siting of the foramen of Magendie $?$ and sometimes doubt as to its very existence; so far as 3 man is concerned these questions were finally settled in 0 the operating theatre.

Our knowledge of the detailed anatomy of the many structures concerned in the manufacture, delivery, and reabsorption of the cerebrospinal fluid has naturally been $N$ helped by the electron microscope and many recent ${ }^{-}$ discoveries receive mention, including some which $\mathrm{O}$ purport to confirm the authors' well-known view con- $N$ cerning the nature and extent of the perivascular space. $\sigma$

The historical sequence is faithfully followed. Some may have believed that the aqueduct was named after $\stackrel{0}{=}$ Jacobus Sylvius; he along with Vesalius, Berengario da $\mathbb{\mathscr { C }}$ Carpi, and Arantius certainly knew of its existence, but ${ }^{+}$ it was Franciscus Sylvius, it seems, who first correctly ${ }^{O}$ described its relations, while it was Arantius (1595) who first called it 'the aqueduct'.

This book is well produced and readable. W. H. MCMENEMEY 